\title{
Potencial antibacteriano do óleo essencial de Lippia alba Mill. associado a luzes de LED
}

\author{
Antibacterial potential of the essential oil of Lippia alba Mill. \\ associated with LED lights
}

Recebido em: 19/09/2020 Aceito em: 11/04/2021

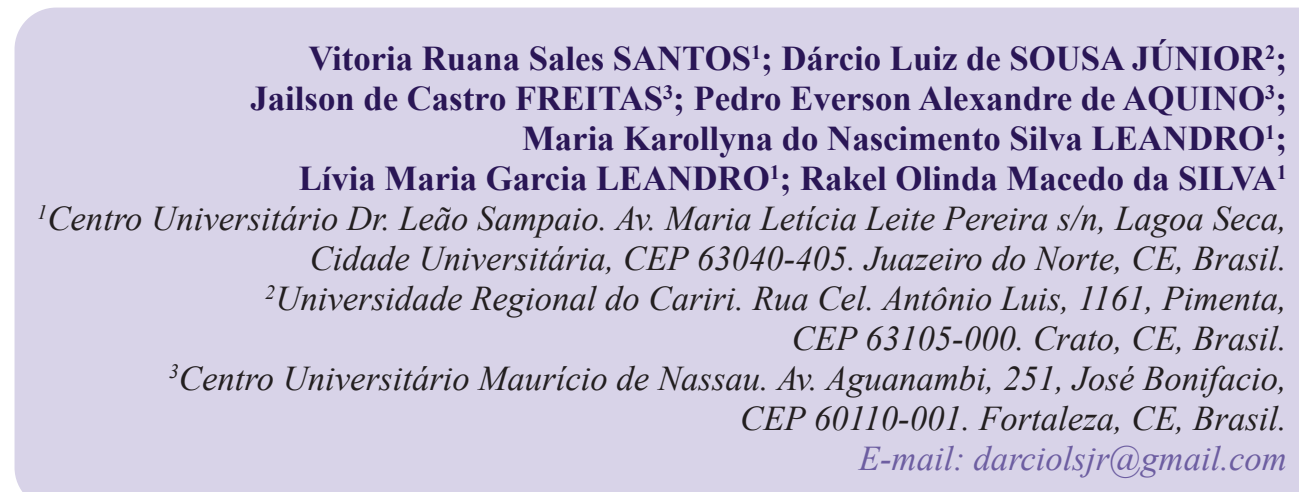

Vitoria Ruana Sales SANTOS ${ }^{1}$; Dárcio Luiz de SOUSA JÚNIOR²; (

Lívia Maria Garcia LEANDRO ${ }^{1}$; Rakel Olinda Macedo da SILVA ${ }^{1}$

Cidade Universitária, CEP 63040-405. Juazeiro do Norte, CE, Brasil. CEP 63105-000. Crato, CE, Brasil. . Av. Aguanambi, 251, José Bonifacio, E-mail:darciolsjr@gmail.com

\section{ABSTRACT}

Lippia alba, also known as erva cidreira, is an aromatic bush occurring throughout Brazil. Its essential oil has many bioactivities, but few studies of its use are associated to phototherapy. The aim of this study was to evaluate the antibacterial activity of the essential oil of Lippia alba (OEL) associated with blue, red, and yellow LED (Light Emitting Diode) lights against strains of Staphylococcus aureus and Escherichia coli. The oil was extracted by the hydrodistillation method. The antibacterial and modulatory activity was performed by the method of gas contact using the oil, LED lights, and antibiotics. All experiments were carried out in triplicate. The OEL has antibacterial potential against all strains tested, with a more expressive result against the multi-resistant strain of E. coli when associated with the LED lights. The modulation of bacterial resistance, both in the combinations of oil + antibiotic + LED lights and oil + antibiotics, showed synergism against the tested multi-resistant strains. Therefore, the essential oil of Lippia alba associated with LED lights has an antibacterial and modulating effect by gas contact. These data may contribute to future research linked to development of new therapeutic strategies to combat resistant microorganisms.

Keywords: phototherapy; biological products; pharmacological sinergism.

\section{RESUMO}

Lippia alba Mill., também conhecida como erva cidreira, é um subarbusto aromático que ocorre em todo território brasileiro. Seu óleo essencial possui muitas atividades, mas ainda são escassos estudos do seu uso associado à fototerapia. $\mathrm{O}$ objetivo desse estudo foi avaliar a atividade antibacteriana do óleo essencial de Lippia alba (OEL) associado a luzes de LED (Light Emitting Diode) azul, vermelha e amarela contra cepas de Staphylococcus aureus e Escherichia coli. O óleo foi extraído pelo método de hidrodestilação. A atividade antibacteriana e moduladora foi avaliada pelo método de contato gasoso utilizando o óleo, luzes de LED 
e antibióticos, os quais foram realizados em triplicata. O OEL possui um potencial antibacteriano frente todas as cepas testadas tendo um resultado mais expressivo na cepa multirresistente de E. coli quando associado a luzes de LED. Na modulação da resistência bacteriana, tanto nas combinações do óleo + antibiótico + luzes de LED como óleo + antibióticos, houve sinergismo frente às linhagens multirresistentes de ambas as cepas testadas. Os resultados obtidos no presente estudo mostraram que o óleo essencial de Lippia alba associado às luzes de LED possui efeito antibacteriano e modulador pelo método de contato gasoso. Estes dados obtidos poderão colaborar com pesquisas futuras que visem o desenvolvimento de novas estratégias terapêuticas no combate de microrganismos resistentes.

Palavras-chave: fototerapia; produtos biológicos; sinergismo farmacológico.

\section{INTRODUÇÃO}

As infecções bacterianas vêm sendo um dos principais agravos de saúde no mundo. A terapia à base de antibacterianos possibilitava um controle sobre este problema; porém, com o passar dos anos os micro-organismos passaram a desenvolver mecanismos de resistências que dificultam o tratamento dessas doenças $(1,2)$.

Estudos realizados acerca da incidência de cepas bacterianas resistentes demonstram que o ambiente comunitário em geral e o ambiente hospitalar são considerados os principais reservatórios destes micro-organismos onde, as principais infecções observadas são as respiratórias, urinárias e cutâneas podendo variar de uma simples infecção até quadros graves como a sepse $(3,4)$.

Segundo um documento publicado pela Organização Mundial de Saúde (OMS, 2017), as principais bactérias que devem ser estudadas no desenvolvimento de pesquisas de novos antibióticos pelo fato de apresentarem um tratamento difícil são espécies Enterobactérias Gram-negativas resistentes a carbapênicos e cefalosporinas, como Escherichia coli e Klebsiella pneumoniae e espécies Gram-positivas, como Staphylococcus aureus resistente a meticilina (MRSA) e vancomicina (5).

Lippia alba também conhecida como erva cidreira é um subarbusto aromático que ocorre em todo território brasileiro, pertencente à família Verbenaceae. Esta espécie é utilizada na medicina popular como analgésico, anti-inflamatório, sedativo e antiespasmódico e estudos demonstraram que o óleo essencial e o extrato metanólico desta espécie apresentam compostos como geranial, neral, $\beta$ - ca- riofileno e carvona, o que respalda seu potencial bioativo e a capacidade de inibir bactérias, fungos e protozoários (6).

A modulação de fármacos se caracteriza pela capacidade que produtos naturais têm de modificar a ação de antimicrobianos possibilitando assim a inversão da resistência bacteriana pela eliminação de plasmídeos ou pela inibição de bombas de efluxo. A combinação entre produtos naturais e fármacos sintéticos possui uma grande relevância uma vez que essa utilização contribui para a diminuição da concentração mínima inibitória dos antibióticos pela minimização dos efeitos secundários e pela ação sinérgica promovida por esse processo $(7,8,9)$.

A fototerapia constitui um eficiente recurso terapêutico onde uma das opções promissoras deste recurso é o Light Emitting Diode (LED) que são diodos semicondutores que emitem luz em diferentes comprimentos de onda. Esta foto-ondulação possui capacidade de atuar na permeabilidade celular, síntese de ATP, proteínas, entre outros processos agindo como antibacteriano e anti-inflamatório a depender do comprimento de onda utilizado $(10,11)$.

As bactérias são os principais microrganismos causadores de doenças. Pode ocorrer agravamento do quadro pelo desenvolvimento de resistência a antimicrobianos. Desta forma, o estudo acerca de Lippia alba, suas atividades e a utilização de seus compostos frente bactérias resistentes é importante, pois, tem potencial de contribuir para o desenvolvimento de novos fármacos antibacterianos. Diante disto, o presente estudo tem como objetivo avaliar a atividade antibacteriana e moduladora do óleo essencial de Lippia alba associada à exposição a LED frente a microrganismos multirresistentes. 


\section{MATERIAL E MÉTODO}

Coleta do material vegetal. As folhas de Lippia alba foram coletadas no horto de plantas medicinais da Universidade Regional do Cariri (URCA), no município de Crato, Ceará, Brasil e uma exsicata da espécie foi depositada no Herbário Dárdano Andrade-Lima (URCA), com o número de registro $n^{0} 5059$.

Extração do óleo essencial das folhas de $\mathbf{L i}$ ppia alba. A extração do óleo essencial das folhas de Lippia alba (OEL) foi realizada pelo método de hidrodestilação utilizando o aparelho tipo Clevenger (Labor Quimi, Brasil), onde as folhas foram trituradas e colocadas em um balão de vidro de 5,0 L juntamente com 2,5 L de água destilada, permanecendo em ebulição por 2 horas. foi adicionado sulfato de sódio anidro $\left(\mathrm{Na}_{2} \mathrm{SO}_{4}\right)$ ao óleo essencial obtido e este foi armazenado sob refrigeração (- 4 $\left.{ }^{\circ} \mathrm{C}\right)$ para conservação da amostra até a realização das análises (12).

Aparelho de LED. O aparelho utilizado durante o procedimento experimental foi o Light Emithing Diodes (NEW-Estética ${ }^{\circledR}$, Brasil) (LED), um diodo emissor de luz da marca NEW-Estética ${ }^{\circledR}$, o qual possui os espectros de luz vermelha, azul e amarela, permitindo também a combinação dessas cores. As luzes utilizadas foram azul, com um comprimento de onda pré-determinado pelo aparelho, de $415 \mathrm{~nm}$, luz vermelha $(620 \mathrm{~nm})$ e luz amarela $(590 \mathrm{~nm})$.

Meios de Cultura e Antibióticos. Os discos com antibióticos gentamicina, amicacina, penicilina $\mathrm{G}$, oxacilina, norfloxacina e ciprofloxacina foram obtidos na LaborClin ${ }^{\circledR}$ Produtos para Laboratórios Ltda, Brasil. Os meios de cultura foram adquiridos de HiMedia Laboratories, India e dimetilsulfóxido (DMSO) de Merck, Darmstadt, na Alemanha.

Microrganismos. Foram utilizadas as linhagens bacterianas padrão de Escherichia coli (ATCC 10536) e Staphylococcus aureus (ATCC 25923) cedidas pelo Instituto Oswaldo Cruz e as linhagens multirresistentes de isolados clínicos Escherichia coli 27 e Staphylococcus aureus 358. As informações acerca das origens e perfil de resistências das cepas utilizadas estão contidas na Tabela 1 . Todas as linhagens foram mantidas em Agar Infusão de Coração (HIA). Para os testes, as linhagens foram suspensas em tubos de ensaio com solução salina para obter uma suspensão com turvação equivalente a 0,5 da escala de McFarlland ( $\left.1 \times 10^{8} \mathrm{UFC} / \mathrm{mL}\right)$.

Tabela 1. Microrganismos utilizados e perfil de resistência das cepas padrão e isolados clínicos.

\begin{tabular}{|l|c|c|}
\hline \multicolumn{1}{|c|}{ Bactérias } & Origem & \multicolumn{1}{c}{ Perfil de Resistencia } \\
\hline Staphylococcus aureus & ATCC 25923 & - \\
\hline Escherichia coli & ATCC 10536 & \\
\hline Escherichia coli 27 & Feridas cirúrgicas & Ast, Amp, Ami, Amox, Ca, Cfc, Cf, Caz, Cip, Clo, Im, Can, Stz, Tet, Tob \\
\hline Staphylococcus aureus 358 & Feridas cirúrgicas & 0xa, Gen, Tob, Ami, Can, Neo, Par, But, Sis, Net
\end{tabular}

Ast: Aztreonam; Amp: Ampicillina; Ami: Amicacina; Amox: Amoxicillina; Ca: Cefadroxila; Cfc: Cefaclor; Cf: Cefalotina; Caz: Ceftazidima; Cip: Ciprofloxacina; Clo: Cloranfenicol; Im: Imipenem; Can: Canamicina; Stz: Sulfametazina; Tet: Tetraciclina; Tob: Tobramicina; 0xa: 0xacilina; Gen: Gentamicina; Neo: Neomicina; Par: Paromomicina; But: Butirosina; Sis: Sisomicina; Net: Netilmicina; (-): Sensibilidade. ATCC: American Type Culture Collection.

\section{Avaliação da atividade antibacteriana por} contato gasoso. Em placas de Petri contendo Agar Mueller-Hinton, foi realizada a semeadura em tapete de cada cepa padrão. O OEL foi utilizado na concentração de $100 \%$. Um disco de papel absorvente semelhante aos discos para os testes de antibiograma foi colocado sobre o semeio e na tampa de cada placa foi acrescentado $10 \mu \mathrm{L}$ do óleo. As placas foram incubadas em estufa por 24 horas a $37{ }^{\circ} \mathrm{C}$ em estufa bacteriológica. Para determinação dos halos de inibição foi utilizada uma régua milimetrada. Todos os testes foram realizados em triplicata (11).

Avaliação da atividade moduladora por contato gasoso. $\mathrm{O}$ ensaio para avaliação da atividade moduladora ocorreu de acordo com o méto- 
do do contato gasoso modificado por Inouye e cols (2001). Em placas de Petri contendo Agar Mueller-Hinton foi realizada a semeadura em tapete de cada cepa multirresistente. Na base das placas inoculadas foram adicionados os discos de antibióticos gentamicina $10 \mu \mathrm{g}$, amicacina $30 \mu \mathrm{g}$, norfloxacin $10 \mu \mathrm{g}$, ciprofloxacin $5 \mu \mathrm{g}$, penicilina G 10U, oxacilina $1 \mu \mathrm{g}$ (LaborClin, Brasil) (13). Na tampa de cada placa foi acrescentado $10 \mu \mathrm{L}$ do óleo essencial, de forma que através da volatilização, ocorresse interação com os discos de antibióticos. Outras placas contendo os discos de fármacos, mas sem o óleo, foram também preparadas para servirem de controle. Após essa etapa, todas as placas foram incubadas por 24 horas a $37{ }^{\circ} \mathrm{C}$ em estufa bacteriológica. Com uma régua milimetrada foram medidos os halos de inibição dos antibióticos na presença e na ausência do óleo testado, para determinação de sinergismo ou antagonismo. Todos os testes foram realizados em triplicata.

Avaliação da atividade antibacteriana e moduladora com exposição ao LED. Para realização destes testes foi utilizada a mesma metodologia referente ao teste de avaliação da atividade antibacteriana e moduladora por contato gasoso. As placas foram subdivididas em quatro grupos onde o primeiro foi submetido à luz de LED azul, o segundo grupo submetido à luz de LED vermelha e o terceiro à luz de LED amarela durante vinte minutos cada placa. $\mathrm{O}$ quarto grupo não foi submetido às luzes de LED. As placas foram incubadas a $37^{\circ} \mathrm{C}$, durante 24 horas em estufa bacteriológica. Os testes foram realizados em triplicata e para determinação dos halos de inibição foi utilizada uma régua milimetrada (11).

Análise estatística. Os ensaios antibacterianos foram realizados em triplicata e os resultados foram expressos em média aritmética \pm desvio padrão, avaliados estatisticamente por meio da análise de variância (ANOVA) e teste de Tukey, utilizando o programa GraphPad Prism 7.0, onde as diferenças foram consideradas significativas quando $p \leq 0,05$.

\section{RESULTADOS E DISCUSSÃO}

No teste realizado pelo método de contato gasoso, o óleo essencial de Lippia alba (OEL) apresentou atividade antibacteriana, observada pela formação de halos, frente a todas as cepas testadas, com um resultado favorável frente a cepa multirresistente de E. coli 27 e $S$. aureus ATCC25923 quando exposta à associação do óleo essencial com as luzes de LED (Tabela 2).

Tabela 2. Atividade antibacteriana de óleo essencial de folhas de Lippia alba (OEL), associada à radiação luminosa.

\begin{tabular}{|l|c|c|c|c|}
\hline \multicolumn{1}{|c|}{ CEPA } & Halo de inibição (mm) & LED AMARELO & LED VERMELHO \\
\hline Escherichia coli (ATCC10536) & SEM LED & LED AZUL & 35 & 30,6 \\
\hline Escherichia coli 27 & 30 & 33,3 & 42 & 43 \\
\hline Staphylococcus aureus (ATCC25923) & 40 & 44,6 & 36,3 & 43,3 \\
\hline Staphylococcus aureus 358 & 30 & 38,3 & 24,3 & 33,3 \\
\hline
\end{tabular}

LED: Light Emitting Diode

A Figura 1 representa os resultados da modulação da amicacina combinada com o OEL e as luzes de LED. Nas combinações frente à cepa de E. coli 27 houve o aumento do halo com a associação do antibiótico e o OEL, assim como na associação do antibiótico com a luz de LED azul onde houve uma menor significância. A associação do antibiótico com o OEL e luzes de LED azul, amarela e vermelha apresentou um resultado ainda mais significante. Nas combinações realizadas frente a cepa de $S$. aureus 358 , houve aumento do halo quando se fez a associação do antibiótico com OEL, com maior significância na associação do antibiótico juntamente com o OEL e as luzes de LED azul, amarela e vermelha. 


\section{lentarma}

Figura 1. Ação da Amicacina em combinação as luzes de LED azul, amarela e vermelha e óleo essencial de folhas de Lippia alba (OEL).

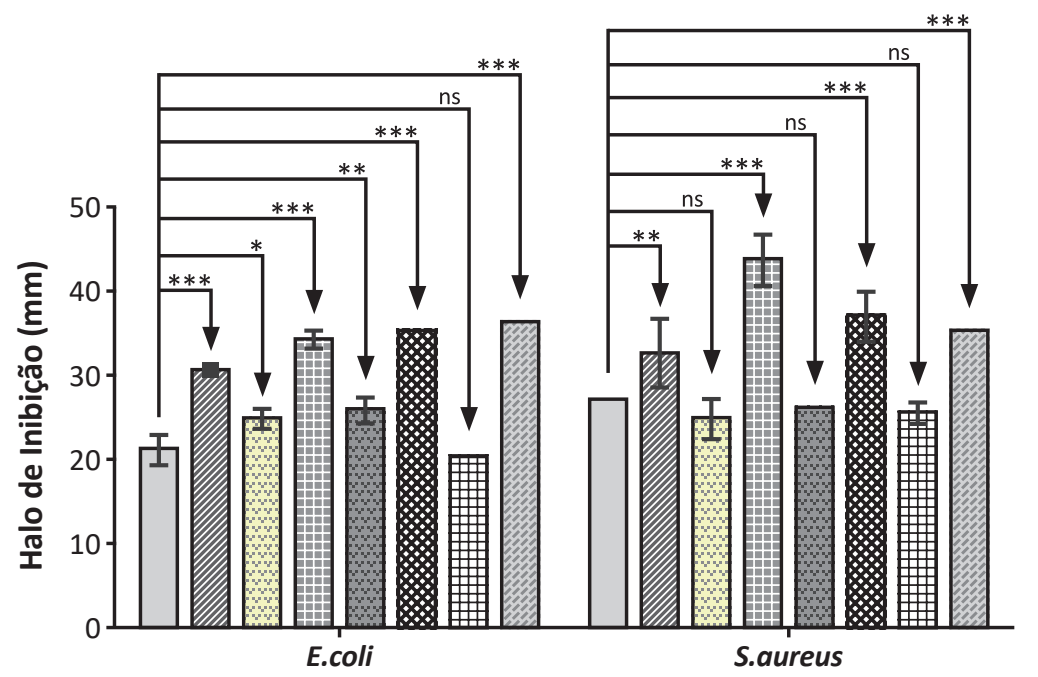

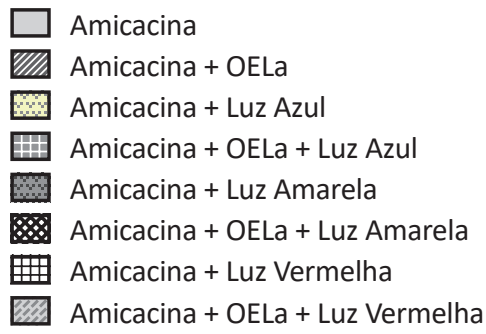

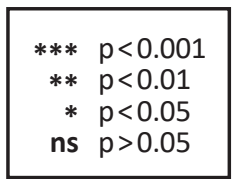

A Figura 2 representa os resultados da modulação da Gentamicina quando combinada com OE es luzes de LED onde, frente a cepas de E. coli 27 houve aumento do halo com a associação do antibiótico e o OEL, tendo um resultado de maior significância quando se fez a associação do anti- biótico, o OEL e as luzes de LED azul, amarela e vermelha. Nas combinações realizadas frente a cepas de $S$. aureus 358 só foram obtidos resultados significativos quando se fez a associação do antibiótico, OEL e as luzes de LED azul, amarela e vermelha.

Figura 2. Ação da Gentamicina em combinação as luzes de LED azul, amarela e vermelha e óleo essencial de folhas de Lippia alba (OEL).

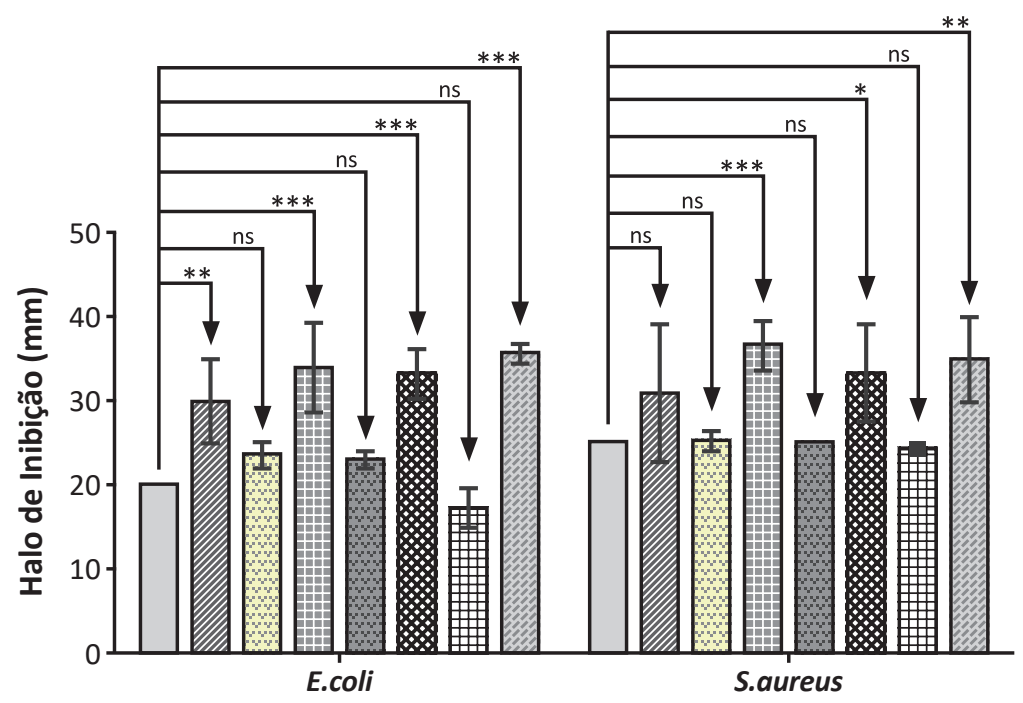

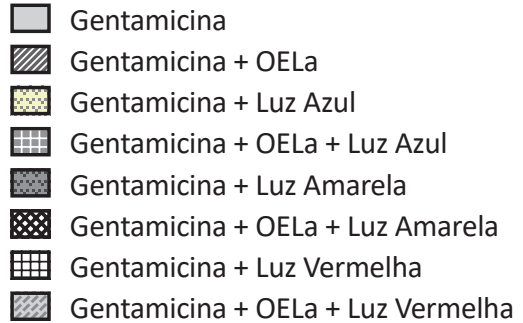

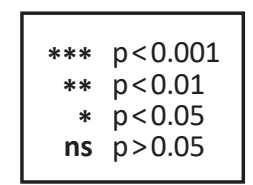

A Figura 3 mostra a modulação da Ciprofloxacina combinada a OEL e luzes de LED. Frente a cepas de E. coli 27 , a associação do antibiótico com o OEL fez com que houvesse um aumento significativo no tamanho do halo quando comparado ao uso somente do antibiótico frente a cepa. 
Esta potencialização da atividade antibacteriana foi também observada quando se realizou a associação do antibiótico, o OEL e as luzes azul, amarela e vermelha. No que diz respeito aos testes realizados frente a cepa de $S$. aureus 358, foi observado aumento dos halos de forma significante somente na associação do antibiótico com o OELa e as luzes de LED azul e amarela, respectivamente.

Figura 3. Ação da Ciprofloxacina em combinação as luzes de LED azul, amarela e vermelha e óleo essencial de folhas de Lippia alba (OEL).

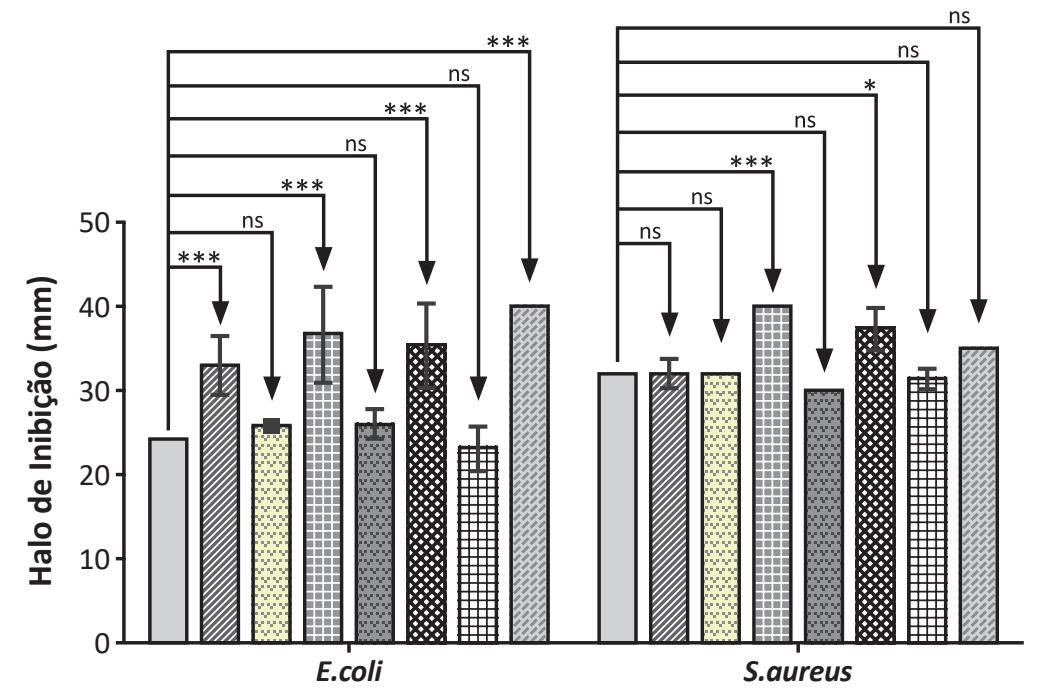

$\square$ Ciprofloxacina
Ciprofloxacina + OELa
Ciprofloxacina + Luz Azul
Ciprofloxacina + OELa + Luz Azul
Ciprofloxacina + Luz Amarela
Ciprofloxacina + OELa + Luz Amarela
Ciprofloxacina + Luz Vermelha
Ciprofloxacina + OELa + Luz Vermelha

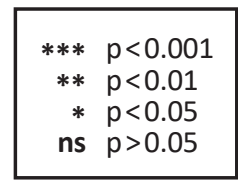

A Figura 4 representa os resultados da modulação de Norfloxacina quando associada a OEL e luzes de LED. Na combinação do antibiótico com o OEL houve aumento dos halos, assim como quando estes foram associados a luzes de LED azul, ama- rela e vermelha no que diz respeito à cepa $E$. coli 27. Foi observado também o aumento dos halos quando $S$. aureus 358 foi submetida a antibiótico associado ao OEL e às luzes de LED azul, amarela e vermelha.

Figura 4. Ação da Norfloxacina em combinação as luzes de LED azul, amarela e vermelha e óleo essencial de folhas de Lippia alba (OEL).
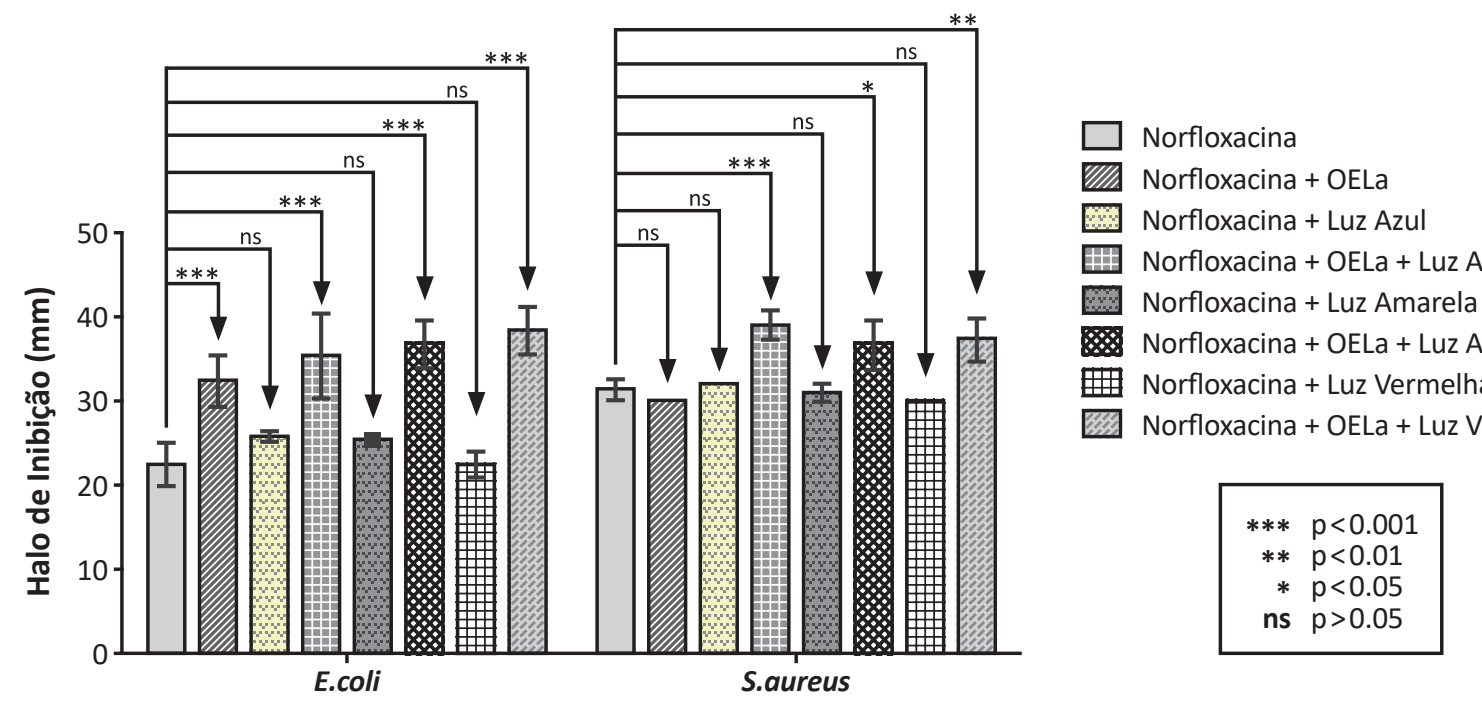
O estudo realizado apresentou algumas limitações. Este modelo de pesquisa é voltado para uma possível utilização do produto natural de forma tópica em associação ao aparelho de LED, sendo o uso oral uma opção mais complexa a ser analisada. Outro obstáculo está relacionado aos compostos isolados do óleo essencial em questão, os quais podem ser responsáveis pela ação demonstrada no estudo, que são de difícil isolamento muitas vezes.

De acordo com o estudo realizado por Machado e cols (2014) foi observada atividade antibacteriana no óleo essencial de Lippia alba pelo método de difusão em Agar em todas as concentrações testadas com um amplo espectro de atividade, onde tanto bactérias Gram-positivas como Gram-negativas foram inibidas, corroborando com o presente estudo (14).

Foi constatada também atividade antibacteriana dos extratos brutos de Lippia alba pela metodologia de difusão em disco de papel onde os resultados obtidos mostraram que os extratos clorofórmico, acetônico e etanólico da raiz foram ativos frente a Staphylococcus aureus, Micrococcus luteus, Bacillus subtilis, Mycobacterium smegmatis, Candida albicans e Monilia sitophila e os extratos hexânico, etanólico e metanólico de folhas inibiram S. aureus, M. luteus, B. subtilis, M. smegmatisi e M. sitophila (15).

A atividade antibacteriana de produtos naturais se dá por diversos fatores como: composição química da planta, processamento do vegetal, concentração do composto utilizado, tipo de microrganismo testado, entre outros fatores. Com base em estudos realizados o óleo essencial de Lippia alba, este possui como principais compostos químicos o citral, limoneno e mirceno, compostos que apresentam atividade antimicrobiana, efeito analgésico e ansiolítico $(15,16)$.

Estudos que contemplem a atividade antimicrobiana de espécies vegetais, assim como sua capacidade de modular fármacos, têm sido bastante discutidos tendo em vista que estas propriedades podem ser uma nova estratégia de tratamento quando a utilização dessas drogas de forma isolada não apresenta eficácia $(17,18)$. Combinações de fármacos antibacterianos e associações destes com produtos naturais vêm sendo aplicadas no combate de microrganismos patogênicos que apresentem resistência a diversas classes de antibióticos, estas combinações tem por finalidade alterar os efeitos destes fármacos seja revertendo a resistência ou potencializando-a (19).

Segundo Pereira e cols (2019), ensaios de Checkerboard demonstraram que o óleo essencial de $L$. alba foi capaz de modular positivamente a ação de antimicrobianos de diversas classes, reduzindo em até 16 vezes a concentração mínima inibitória tanto pelo método de disco-difusão quanto pelo método de contato gasoso (20). O presente estudo também demonstrou que o OEL contribuiu positivamente na atividade de todos os antibióticos testados indicando um efeito sinérgico. Em outro estudo realizado, o óleo essencial de $L$. alba interferiu na ação de diversos aminoglicosídeos e a atividade antibacteriana da gentamicina contra cepas de $S$. aureus foi aumentada cerca de $275 \%$ quando submetido a $12 \%$ do óleo essencial (21).

A fototerapia promove alterações bioquímicas na membrana celular que acabam por causar danos em sua estrutura, ela também pode inibir a respiração celular por atingir a mitocôndria, fazendo com que ocorra problemas na célula bacteriana impedindo seu processo de divisão. Esta terapia pode ainda inativar enzimas que são responsáveis por aumentar a permeabilidade celular e pelo metabolismo celular (22). Segundo Lipovskye cols (2010), a inativação fotodinâmica e a fototerapia por meio do uso de aparelhos de LED, vem sendo bastante estudada tendo em vista que estudos realizados frente a cepas de Escherichia coli e Staphylococcus aureus demonstraram que estes métodos são eficazes na erradicação de bactérias (23).

A luz de LED azul é descrita na literatura como apresentando atividade bactericida, por um mecanismo chamado stress oxidativo. Estudos também comprovaram que a luz de LED vermelha possui uma capacidade de penetração mais profunda e que essa capacidade influencia significativamente no seu potencial de formar halos de inibição $(24,25)$. O óleo essencial de Eugenia jambolana apresentou potencial antibacteriano e modulador quando testado frente cepas de $E$. coli e $S$. aureus em associação com luzes de LED, tanto pelo método de contato gasoso quanto pelo método de microdiluição, corroborando com o presente estudo (20). 
Segundo Matias (2018), a utilização do óleo essencial de Cordia verbanacea DC., associado a luzes de LED, não apresentou potencial antibacteriano pelo método de contato gasoso, porém, sua associação a antibióticos juntamente com a exposição às luzes de LED apresentou efeito modulador da resistência bacteriana (26). Estes resultados coincidiram com os obtidos neste estudo, tendo em vista que os resultados de maior significância em sua maioria foram obtidos quando realizou-se a associação dos antibióticos com o OEL e a exposição às luzes de LED.

Os resultados com valores estatisticamente não significantes podem ser justificados pela estrutura de bactérias Gram-negativas, que possuem membrana externa formando um envelope, o que torna difícil a ação de produtos naturais e antimicrobianos (27). No entanto, foi possível observar resultados consideráveis frente a cepas de E. coli na modulação com Amicacina, Gentamicina, Ciprofloxacina e Norfloxacina, tendo em vista que os halos de inibição formados indicaram efeito sinérgico. Dessa forma, a metodologia empregada pode modificar a resistência das bactérias Gram-negativas e Gram-positivas.

\section{CONCLUSÃO}

O óleo essencial de Lippia alba, associado a luzes de LED, possui efeito antibacteriano e modulador pelo método de contato gasoso. O estudo mostrou a importância e necessidade de outros estudos mais aprofundados acerca dessa espécie e sua associação com luzes de LED, visando o desenvolvimento de novas estratégias terapêuticas no combate de micro-organismos resistentes.

\section{REFERÊNCIAS}

1. Baptista MGFM. Mecanismos de resistência bacteriana. [Dissertação]. Lisboa: Universidade Lusófona de Humanidades e Tecnologias. 2013.

2. Sousa Júnior DL, Silva Benjamim ÍM, Teotônio LEO, Gonçalves FJ, Salviano CMT, Leandro RC, Lopes MJP, Aquino PEA, Leite NF. Efeito antimicrobiano e modulador do extrato hidroalcoólico de Genipa americana (Jenipapo). Saúde 2019;45(1). DOI: 10.5902/ 2236583433472

3. Esteves DC, Santos Silva HP, Pinto KSVR, Sonvesso BL, Keller R, Rodrigues MVP. Avaliação de Conservação da Viabilidade de Staphylococcus aureus e Escherichia coli sob Influência de Fluídos Biológicos em Superfícies Secas. Colloq Vitae. 2014;6(2):31-42. DOI: 10.5747/ cv.2014.v06.n2.

4. Neves JD Vandesmet VCS, Mendes CFC, Sousa Júnior DL, Santos NM, Cordeiro PMD, Leandro LMG. Análise bacteriológica de jalecos de profissionais da saúde de uma clínica escola na cidade de Juazeiro do Norte, Ceará. Rev Interfaces Saúde, Hum Tecnol. 2016;3(9). DOI: 10.16891/2317-434X.535

5. WHO. Global priority list of antibiotic-resistant bacteria to guide research, discovery and development of new antibiotics, Geneva: World Health Organization, 2017.

6. Soares BV, Cardoso ACF, Campos RR, Gonçalves BB, Santos GG, Chaves FCM, Chagas EC, TavaresDias M. Antiparasitic, physiological and histological effects of the essential oil of Lippia origanoides
(Verbenaceae) in native freshwater fish Colossoma macropomum. Aquaculture. 2017;469:72-78. DOI: 10.1016/j.aquaculture.2016.12.001

7. Alves EF, Santos BS, Matias EFF. Avaliação da atividade antibacteriana e modulatória da fração hexânica do extrato hexânico de Cordia verbenacea DC. Rev Interfaces Saúde, Hum Tecnol. 2014;2(5). 10.16891/ 2317.434X.96.

8. Nascimento EM, Aquino PEA, Pereira NLF, Andrade JC, Oliveira CDM, Guedes TTDAM, Sousa Júnior DL, Coutinho HDM, Menezes IRA, Veras HNH. Estudo fitoquímico e potencial antibacteriano do látex de Himatanthus drasticus (Mart.) Plumel. Biota Amazôn. 2018;8(4):28-32. DOI: 10.18561/2179-5746/ biotaamazonia.v8n4p28-32

9. Ferreira JA, Sousa Júnior DL, Marques AEF, Carvalho Mendes R. Prospecção Fitoquímica e Análise da Atividade Antimicrobiana e Moduladora in Vitro do Extrato Hidroalcoólico das Folhas de Senna spectabilis. Ens Ciênc. 2019;23(3):262-267. DOI: 10.17921/1415-6938. 2019v23n3p262-267

10. Meyer PF, Araújo HG, Carvalho MGF, Tatum BIS, Fernandes ICAG, Ronzio AO, Pinto MVM. Avaliação dos efeitos do LED na cicatrização de feridas cutâneas em ratos Wistar. Fisioter Bras. 2010;11(6):428-32.

11. Silva ÁDL, Monteiro MFG, Sousa Júnior DL, Macêdo NS, Saraiva CRN, Nascimento Silva-Leandro, M. K, Aquino PEA, Macedo da Silva RO, Leandro LMG. 
Atividade antibacteriana e moduladora do óleo essencial de Allium sativum L. (Alho). Visão Acad. 2020;20(4). DOI: $10.5380 /$ acd.v20i4.70344

12. Matos, FJDA, Machado MIL, Craveiro AA, Alencar JW, Barbosa JM, Cunha EVL, Hiruma CA. Essential oil of Mentha $x$ villosa Huds. from Northeastern Brazil. J Essent Oil Res. 1999;11(1):41-44. DOI: 10.1080/10412905. 1999.9701066.

13. Inouye $\mathrm{S}$, Takizawa $\mathrm{T}$, Yamaguchi H. Antibacterial activity of essential oils and their major constituents against respiratory tract pathogens by gaseous contact. J Antimicrob Chemother. 2001;47(5):565-573. DOI: 10.1093/jac/47.5.565.

14. Machado TF, Nogueira NAP, Pereira RDCA, Sousa CTD, Batista VV. The antimicrobial efficacy of Lippia alba essential oil and its interaction with food ingredients. Braz J Microbiol. 2014;45(2):699-705. DOI: 10.1590/ S1517-83822014000200045.

15. Aguiar JS, Costa MC, Nascimento SC, Sena KX. Atividade antimicrobiana de Lippia alba (Mill.) NE brown (Verbenaceae). Rev Bras Farmacogn. 2008; 18(3):436-440. DOI: 10.1590/S0102-695X20080003 00018.

16. Bertini LM, Pereira AF, Oliveira CD, Menezes EA, Morais SD, Cunha FA, Cavalcanti ESB. Perfil de sensibilidade de bactérias frente a óleos essenciais de algumas plantas do nordeste do Brasil. Infarma. 2005;17(3-4):80-83.

17. Santos FFP, Leandro LMG, Macedo RO, Martins Guedes TTA, Nascimento Silva MK, Ferreira MBS, Sousa Júnior DL, Sousa PWF, Carvalho MAJ, Barbosa TM, Aquino PEA. Avaliação fitoquímica, antibacteriana e modulatória dos extratos metanólico e hexânico da folha de Eugenia uniflora L. Visão Acad. 2019;20(1). DOI: 10.5380/acd. v20i1.64219

18. Araújo ACJ, Freitas PR, Barbosa CRS, Muniz DF, Rocha JE, Araújo Neto JB, Silva MMC, Moura TF, Pereira RLS, Ribeiro-Filho J, Silva LE, Amaral W, Deschamps C, Tintino SR, Iriti M, Vitalini S, Coutinho HDM. Essential Oil of Croton ceanothifolius Baill. Potentiates the Effect of Antibiotics against Multiresistant Bacteria. Antibiotics 2020;9(1):27. DOI: 10.3390/antibiotics 9010027
19. Coutinho HD, Costa JG, Siqueira-Júnior JP, Lima EO. Atividade anti-estafilocócica in vitro de Hyptis martiusii Benth contra linhagens de Staphylococcus aureus resistentes à meticilina: MRSA. Rev Bras Farmacogn. 2008; 18:670-675. DOI: 10.1590/S0102-695X2008000500005.

20. Pereira PIO, Rodrigues ML, Dodou HV, Medeiros SC, Nogueira NAP. Avaliação dos efeitos antimicrobiano e modulador do óleo essencial das folhas do quimiotipo I de Lippia alba (Mill.) N. E. BROWN. Encontros universitários da UFC. 2017;2(1):1.

21. Veras HN, Campos AR, Rodrigues FF, Botelho MA, Coutinho HD, Costa JGD. Lippia alba (Mill.) NE essential oil interfere with aminoglycosides effect against Staphylococcus aureus. J Essent Oil Bear Pl. 2011; 14(5):574-581.DOI:10.1080/0972060X.2011.10643974.

22. Grebeňová D, Kuželová K, Smetana K, Pluskalová M, Cajthamlová H, Marinov I, Fuchs O, Souček J, Jarolím P, Hrkal Z. Mitochondrial and endoplasmic reticulum stress-induced apoptotic pathways are activated by 5-aminolevulinic acid-based photodynamic therapy in HL60 leukemia cells. J Photochem Photobiol B. 2003; 69(2):71-85. DOI: 10.1016/S1011-1344(02)00410-4.

23. Lipovsky A, Nitzan Y, Gedanken A, Lubart R. Visible light-induced killing of bacteria as a function of wavelength: Implication for wound healing. Lasers Surg Med. 2010;42(6):467-472. DOI: 10.1002/1sm.20948.

24. Paschoal FM, Ismael APPB. A ação da luz no tratamento da acne vulgar. Surg Cosmet Dermatol. 2010; 2(2):117-123

25. Araújo AR, Silva FS, Moreira NV, Araújo BHA, Armanelli AP, Silva ACR. A luz como forma de tratamento da acne vulgar: uma revisão sistemática. Fisioter Bras. 2018;19(2):202-214. DOI: 10.33233/fb.v19i2.1319.

26. Matias EFF. Avaliação da atividade antibacteriana e moduladora do óleo essencial de Cordia verbenacea DC. associado às luzes de LED. Rev Interfaces, Saúde, Hum Tecnol. 2018;5(14):07-14. DOI: 10.16891/2317-434X. v5.e14.a2017.pp07-14.

27. Holley RA, Patel D. Improvement in shelf-life and safety of perishable foods by plant essential oils and smoke antimicrobials. Food Microbiol. 2005;22(4):273-292. DOI: $10.1016 /$ j.fm.2004.08.006. 